\title{
ANALYZING THERMOPHYSIOLOGICAL COMFORT AND MOISTURE MANAGEMENT BEHAVIOR OF COTTON DENIM FABRICS
}

\author{
Selin Hanife Eryuruk* \\ Textile Technologies and Design Faculty, Istanbul Technical University, Istanbul, Turkey \\ *Corresponding author. E-mail: eryuruk@itu.edu.tr
}

\begin{abstract}
:
Comfort properties of garments are influenced by fiber properties, fabric properties, and applied finishes. Denim garments are widely used apparels, and they are processed with different industrial finishing treatments. Finishing treatments and fabric weight have a great influence on the thermal comfort of denim fabrics. The aim of this paper was to evaluate the effects of finishing treatments (rigid, bleaching, resin, softener) on the thermophysiological comfort and moisture management properties of denim fabrics considering three weight categories (light, medium, heavy). The thermophysiological comfort (thermal resistance, thermal absorptivity, air permeability, water vapor permeability tests) and liquid moisture transport capabilities (transfer wicking and drying behavior of fabrics) were measured and analyzed statistically. As a result of the study, fabric weight and finishing had been found to be important parameters for the comfort properties of denim fabrics. As a conclusion, it could be stated in the light of the results that the fabric weight type (light, medium, heavy) had a significant impact on the fabric thermophysiological comfort properties.
\end{abstract}

\section{Keywords:}

Denim fabrics, thermophysiological comfort, moisture management, fabric weight

\section{Introduction}

Today, denim garments are demanded by people of all ages in the global apparel market because of their versatile appearance and strength. Different value-adding processes and some special techniques and finishes are applied to make denim look beautiful and more desirable. These physical and chemical treatments are used to improve look, feel, or performance of a fabric, but the effects of these processes on fabric performance properties must be evaluated in detail.

Clothing is an open system, and there are physical, physiological, and neurological processes that determine the comfort level of humans. Heat and moisture transfer, thermal balance, thermoregularity responses, and other interactions between body and environment determine the overall comfort status of the wearer. Heat loss and heat gain must be balanced for a good thermoregularity mechanism, and it is mainly related to thermal resistance and thermal absorptivity [1-5]. The internal body temperature of human beings is constant, and it must be maintained in a very narrow range. When heat production level of the human body is above normal, sweating and sweat evaporation on the surface of the skin is responsible for heat loss. Liquid sweat accumulated on the skin surface or in the inner layer of clothing should be transferred to the outer environment to allow the evaporation of the liquid and to prevent the sense of dampness [6,7]. When water vapor concentration in a clothing system exceeds the saturation level for the local temperature, condensation takes place throughout the layers of the clothing system causing uncomfortable feeling
[8]. Mainly air permeability, water vapor permeability, and relative water vapor permeability determine the transportation of moisture through the fabric.

There are many studies in the literature concerning the effects of different finishing properties on the mechanical properties of denim fabrics [9-17]. However, there are not enough studies about the thermophysiological comfort properties of denim fabrics. Özdil compared the performance characteristics of five different denim fabrics with elastane and found that elastane usage in denim fabrics increased their comfort properties positively [18]. Hes and Mangat investigated the effect of industrial washing on thermal comfort of denim fabrics and found that different finishes had a significant impact on thermal comfort of denim fabrics [19]. Haq et al. analyzed bulk, surface, and transfer properties of the chlorine-bleached denim clothes [20]. They concluded that bleaching decreased the tensile strength of denim and improved the hand roughness and color fastness to rubbing. Halleb et al. evaluated the effect of four different washes on the denim fabric tactile properties using a sensory analysis that was assessed by a trained panel [21]. Çoruh et al. developed a 19-item scale to evaluate physical comfort and some problems that denim jeans users experience during their daily physical activities [22]. In our previous studies, in order to evaluate the effects of elastane and finishing processes on the performance properties of denim fabrics, some mechanical properties, thermal comfort properties, wicking, drying and water vapour permeability values were analyzed using cotton and cotton-elastane blended denim fabrics $[23,24]$. 
As seen from the previous researches, thermal comfort properties of denim fabrics were rarely analyzed. The aim of this study was to determine the effect of different finishing processes and also fabric weight types (light, medium, heavy) on the thermophysiological comfort (thermal resistance, thermal absorptivity, air permeability, water vapor permeability tests) and liquid moisture transport capabilities (transfer wicking and drying behavior of fabrics) of denim fabrics. A series of experiments and analyses were performed to study heat, water, and moisture transferring rates to evaluate the comfort properties of the fabrics. Thermal resistance, thermal absorptivity, water vapor permeability, relative water vapor permeability, air permeability, transfer wicking, and water evaporation rate (WER) were calculated after each finishing process. The results were analyzed using the IBM SPSS 25 software.

\section{Materials and methods}

\subsection{Materials}

Bleaching, resin, and softener treatments were applied to $100 \%$ cotton denim fabrics. The samples were woven using $3 / 1 \mathrm{Z}$ twill weave in three different weights (light, medium, heavy) to show the effect of fabric weight on comfort. Ring spun yarns were used to produce fabrics. To obtain different fabric weights, light weight denim fabrics were produced using 50 tex in the warp yarn and 36 tex in the weft yarn; medium weight denim fabrics were produced using 60 and 62 tex for weft and warp yarns; heavy weight denim fabrics were produced using 65 and 70 tex for warp and weft yarns. Then, fabrics were processed using three different finishing treatments (resin, bleaching, softener).

Samples were conditioned for $48 \mathrm{~h}$ in the atmospheric conditions of temperature $20 \pm 2^{\circ} \mathrm{C}$ and relative humidity $65 \pm 2 \%$, before the measurements on the samples were taken. The thickness

Table 1. Fabric properties

\begin{tabular}{|c|c|c|c|c|c|c|}
\hline Fabric code & Finishing type & Weight type & $\begin{array}{l}\text { Warp density } \\
\text { (ends/cm) }\end{array}$ & $\begin{array}{l}\text { Weft density } \\
\text { (picks/cm) }\end{array}$ & Weight $\left(g / m^{2}\right)$ & $\begin{array}{c}\text { Thickness } \\
\text { (mm) }\end{array}$ \\
\hline 1.1 & \multirow{3}{*}{$\begin{array}{l}\text { Rigid (raw } \\
\text { fabric) }\end{array}$} & Light & 28 & 22 & 210.5 & 0.48 \\
\hline 1.2 & & Medium & 25 & 18 & 356.6 & 0.62 \\
\hline 1.3 & & Heavy & 28 & 20 & 402.9 & 0.70 \\
\hline 2.1 & \multirow{3}{*}{$\begin{array}{l}\text { Bleaching } \\
\text { treatment }\end{array}$} & Light & 24 & 20 & 200.6 & 0.62 \\
\hline 2.2 & & Medium & 28 & 22 & 348.0 & 0.75 \\
\hline 2.3 & & Heavy & 30 & 24 & 375.8 & 0.82 \\
\hline 3.1 & \multirow{3}{*}{ Resin treatment } & Light & 27 & 17 & 201.4 & 0.46 \\
\hline 3.2 & & Medium & 28 & 20 & 346.1 & 0.59 \\
\hline 3.3 & & Heavy & 26 & 20 & 387.1 & 0.65 \\
\hline 4.1 & \multirow{3}{*}{$\begin{array}{l}\text { Softener } \\
\text { treatment }\end{array}$} & Light & 24 & 16 & 217.5 & 0.60 \\
\hline 4.2 & & Medium & 32 & 17 & 360.6 & 0.75 \\
\hline 4.3 & & Heavy & 30 & 22 & 385.8 & 0.80 \\
\hline
\end{tabular}

was measured according to standard ASTM D 1777-64 under $20 \mathrm{~g} / \mathrm{cm}^{2}$ pressure with $0.01 \mathrm{~mm}$ precision.

\subsection{Method}

Table 2 shows the finishing processes for denim fabrics in detail.

Alambeta was used to test thermal absorptivity and thermal resistance of the fabrics [25]. The Alambeta instrument simulates the dry human skin, and its working principle is based on the mathematical processing of time course of heat flow passing through the fabric. The Permetest instrument was used to measure water vapor resistance and water vapor permeability according to the ISO 11092:2014 standard [26]. The air permeability of the samples was measured by using the Prowhite test apparatus according to standard EN ISO 9237:199519 by applying $100 \mathrm{~Pa}$ constant air pressure and $20 \mathrm{~cm}^{2}$ sample size [27]. As conducted in the study of Fangueiro et al., drying capabilities were evaluated by calculating WERs [28]. The specimens were prepared $200-200 \mathrm{~mm}$ in dimensions and weighed. The amount of water was $30 \%$ of the dry specimens' weight, and it was used to wet the specimens. The changes in weights with time were recorded to calculate WER values. Each denim sample was tested five times for all mentioned tests.

\section{Experimental results}

\subsection{Thermophysiological comfort properties}

Heat transfer characteristics of fabrics are very important for thermal comfort and protection against weather conditions. Insulation properties of clothing are caused by the small air pockets separated from each other to prevent air from migrating through the material. Thermal resistance gives thermal
insulation property of a fabric. The results of thermal resistance insulation property of a fabric. The results of thermal resistance 
Table 2. Finishing processes

\begin{tabular}{|c|c|}
\hline Treatments & Processes \\
\hline Rigid fabric & \begin{tabular}{r} 
Woven denim fabric, 3/1 Z twill, with no treatment \\
\hline Resin treatment \\
Bleaching treatment \\
based), and water applied with a spray gun homogeneously throughout the surface
\end{tabular} \\
\hline Softener treatment & $\begin{array}{r}\text { Desizing process with alpha amylase and dispersing material, washing in hot water. Bleaching } \\
\text { activation using acidic benzoyl chloride-based activator. Rinsing and two-step bleaching using } \\
\text { NaOCl. Neutral washing, rinsing, squeezing and drying fabrics }\end{array}$ \\
\hline $\begin{array}{r}\text { Desizing process with alpha amylase and dispersing material, washing in hot water. Softening } \\
\text { with microsilicone and fatty acids. Squeezing and drying }\end{array}$ \\
\hline
\end{tabular}

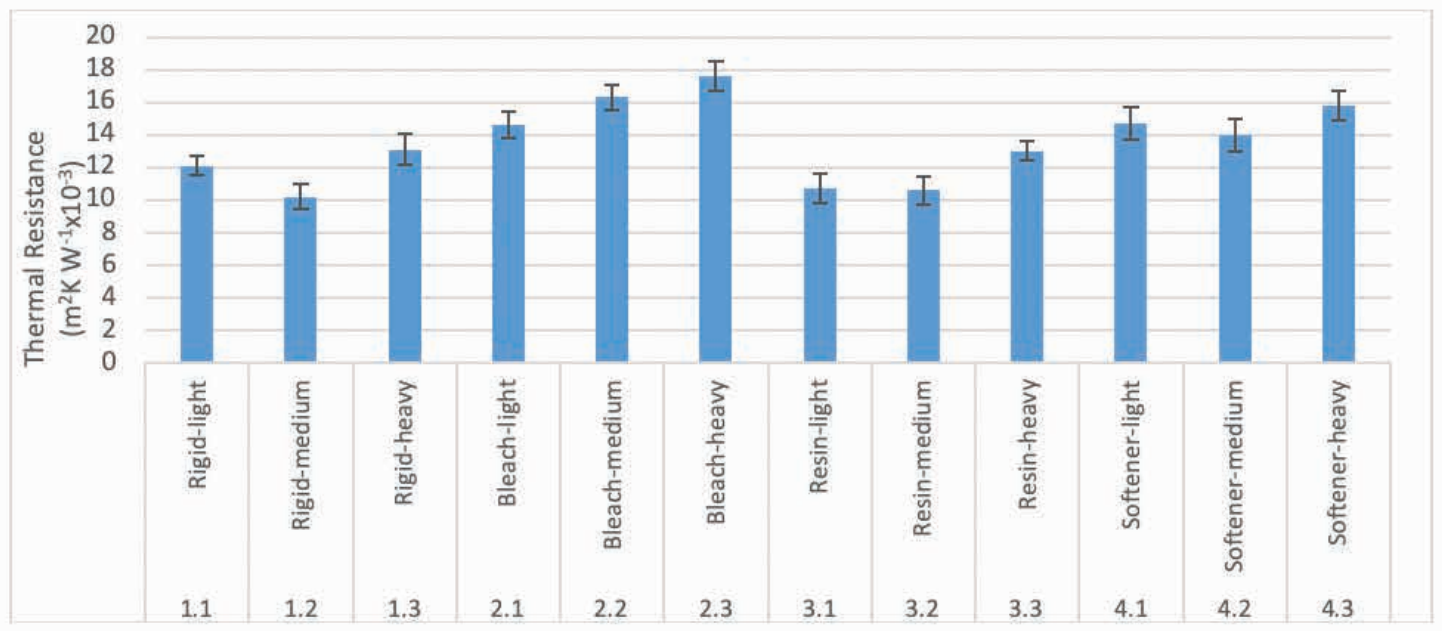

Figure 1. Thermal resistance results of denim fabrics.

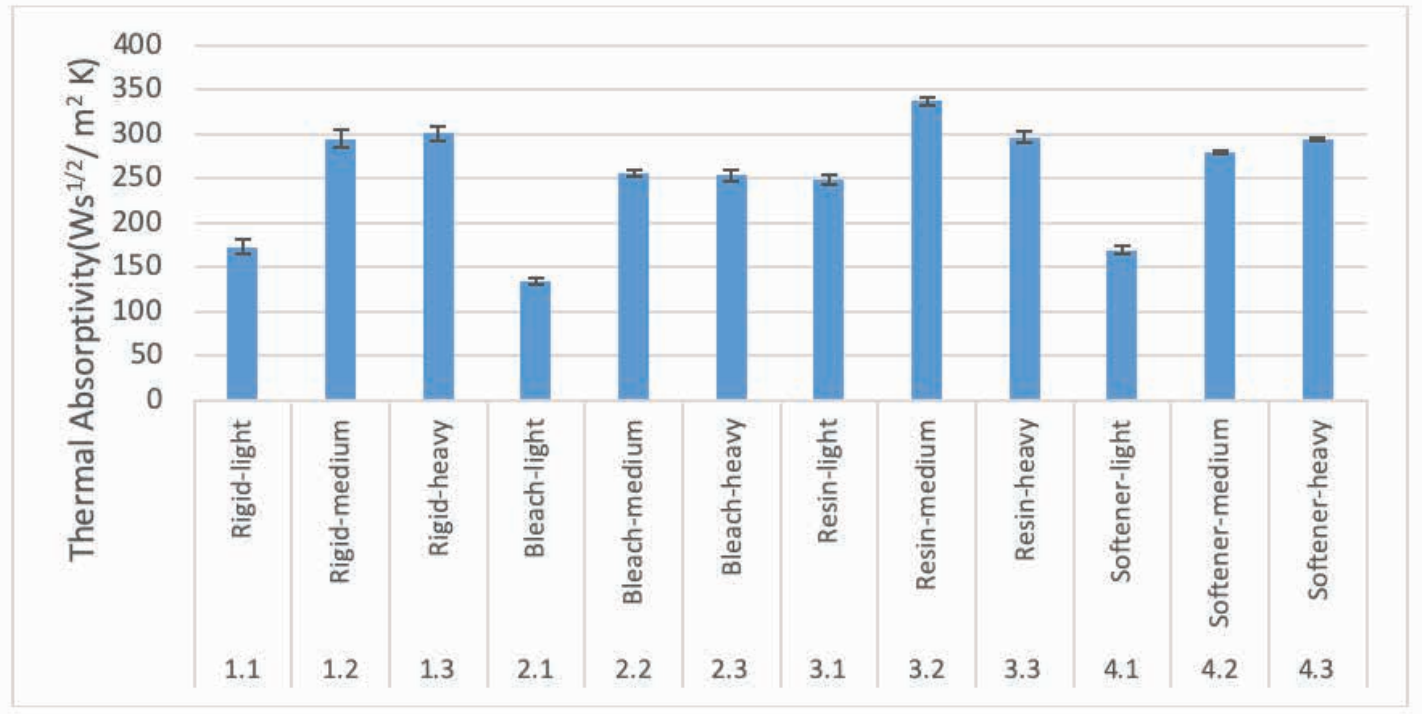

Figure 2. Thermal absorptivity results of denim fabrics.

of fabrics are given in Figure 1. It was generally observed that thermal resistance values were increased as the fabric weights increased. Bleaching and softening processes increased the thermal resistance values very much because they increased the fabric thickness values, created more area and air inside the fabric structure, and led to more insulation. Resin application created more stiff fabric structure by decreasing yarn and fabric hairiness and decreased fabric thermal resistance values.

Thermal absorptivity of fabrics is influenced by surface smoothness; if the contact area between fabric and skin increases, heat flow increases. As seen from Figure 2, as the fabric thicknesses were increased from lightweight to 
heavy weight, thermal absorptivity values increased. Rigid denim fabrics made without any prewash had higher thermal absorptivity values because of their stiff fabric structure and smooth surface. Fabric weight had an increasing effect on thermal absorptivity of rigid fabrics. Softening and bleaching applications decreased thermal absorptivity by creating more spacing that is interior. Resin fabric structure with medium and high weights had also the highest level of thermal absorptivity. As a general trend, as the fabrics weight increased from lightweight to medium weight, thermal absorptivity increased, but from medium to heavy weight, no significant change has been observed.

Air permeability is the tendency to air penetration and affects the thermal insulation of the fabric. In the study, it was observed that due to the compact structures of fabrics with higher weights, air permeability results of fabrics were getting lower as the fabric weights were increased (Figure 3). Denim fabrics with higher fabric weights reduced spaces between yarns and decreased air passage.
Vapor transmission through the fabric structure was mainly influenced by fabric thickness. As shown in Figure 4, as the fabric weight and also fabric thickness values were getting higher, water vapor permeability values of fabrics decreased. As the fabric weight increased, its ability to hold moisture increased.

Water vapor resistance is the ability of a fabric to allow moisture vapor to be transmitted through it. Water vapor resistance values of denim fabrics are shown in Figure 5. As it can be expected, the higher the fabric weight, the higher the water vapor resistance values obtained. The most important conclusion was that heavy fabric structures had higher water vapor resistance results that were not suitable for human comfort. Water vapor resistance values increased dramatically as the fabric weight increased for rigid and resin fabrics. Bleached and softened fabrics had lower resistance values because of greater thickness values creating more area for transmitting water vapor. As the fabric thicknesses increased, water vapor resistance values decreased because there was

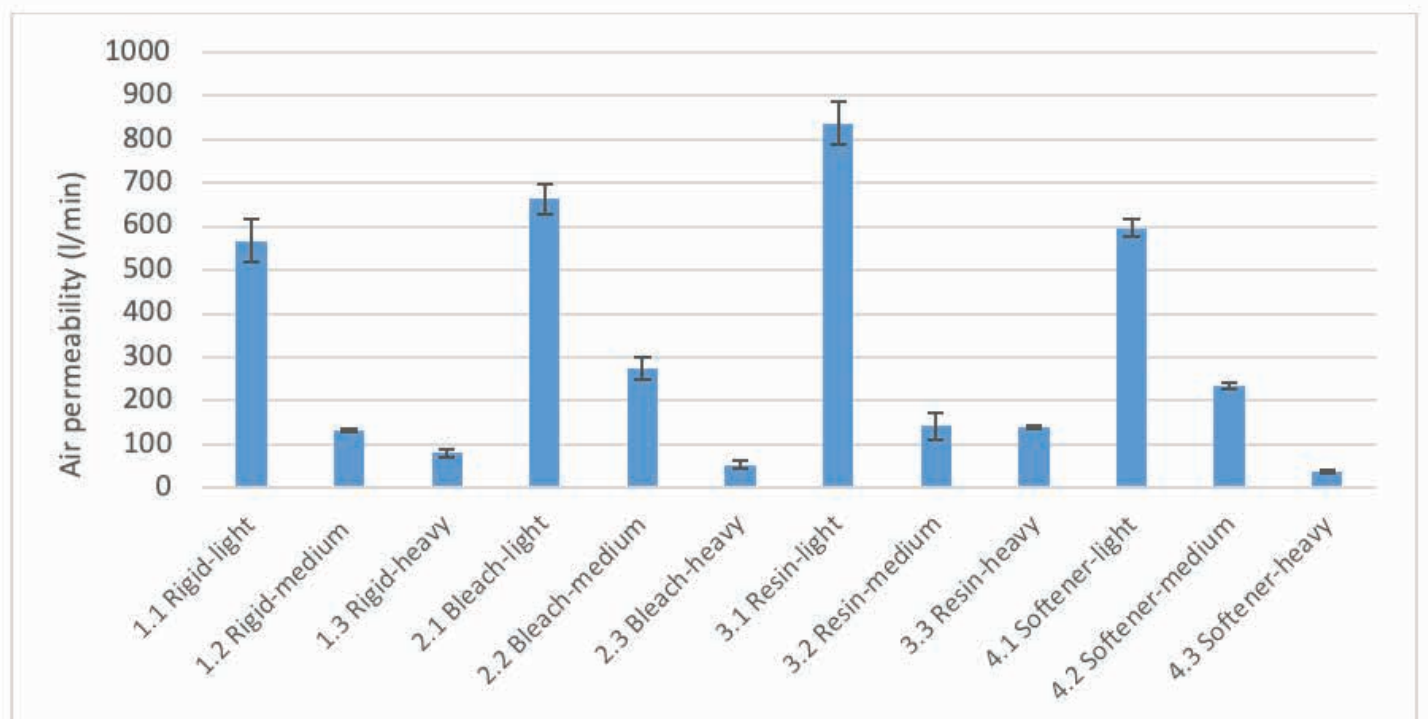

Figure 3. Air permeability results of denim fabrics.

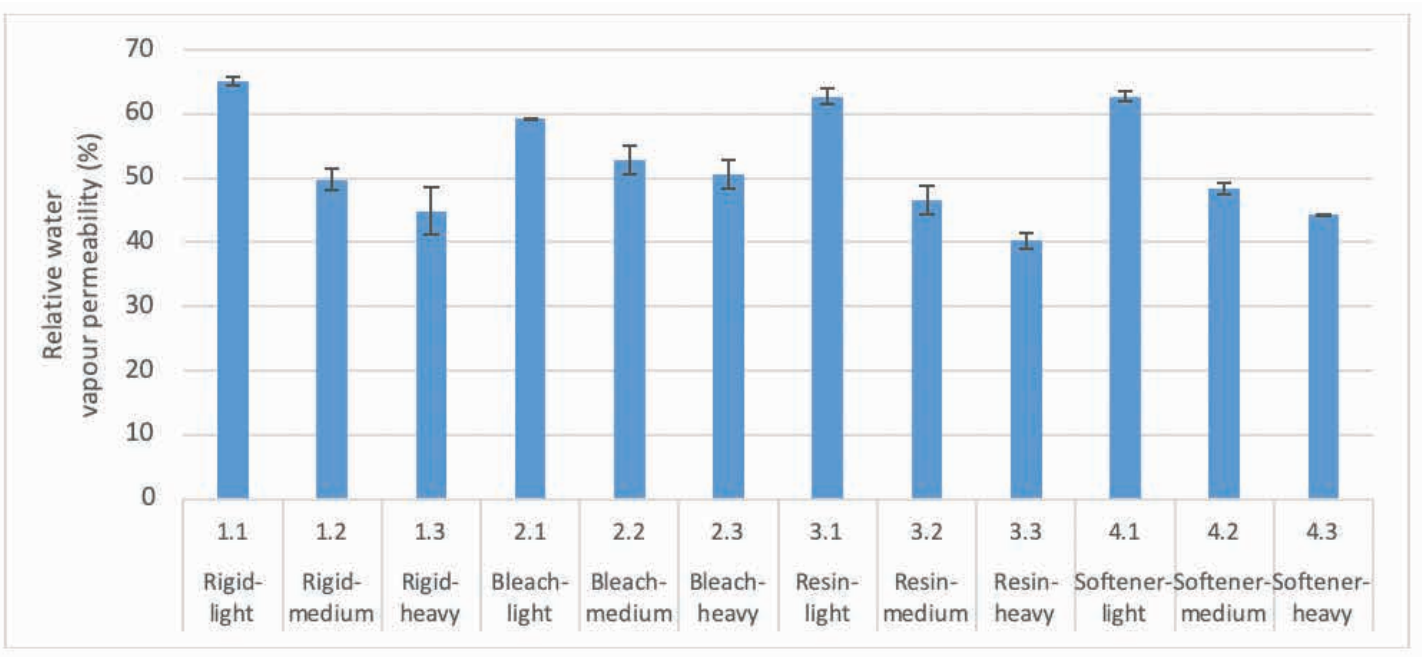

Figure 4. Relative water vapor permeability results of denim fabrics. 
more space within the fabric structure for the passage of water vapor.

\subsection{Transfer wicking and drying results}

Transfer wicking results are shown in Figure 6. Transfer wicking is the transmission of liquid water through the thickness of a fabric. As stated by the researches, fiber type (hydrophobic, hydrophilic), fabric structure (mass, thickness), and finishing treatments had certain effects on the wetting and wicking properties of a fabric $[29,30]$. It can be seen from Figure 7 that as the fabric weight increased, transfer wicking values decreased because water holding capabilities of fabrics increased. Bleaching and softening treatments had significant influences on the transfer wetting values of fabrics. Softened fabrics had highest transfer wicking values because of the increase in fabric thickness. Wicking behavior of a fabric was strongly influenced by fabric weight and thickness values [30].

The length of time required for a garment to dry while being worn is therefore important in maintaining a desired level of "comfort" and minimizing the additional weight from the liquid that the garment may have absorbed. Evaporation of water/ sweat is a mechanism by which fabric and clothing dries during wear and also cools the human body by taking the required heat energy from the human body for the process [1].
Figure 7 shows the WERs of the samples. The WER values showed a decreasing trend when the fabric thicknesses increased. The drying is mainly related to the fabric density of the woven fabrics, so drying times are longer for heavy weight and thick fabrics for the same fabric construction. Heavy weight fabrics $4.3,1.3,2.3$, and 3.3 had the highest drying time values. It may be due to the fact that the total contact area of fibers holding water is higher in heavy weight fabrics because of the higher fiber volume fraction in their structure. Denim fabrics with codes 3.1, 3.2, and 2.1 had the fastest drying times because of their lower weights. Moreover, finishing type was found to have a big influence on the drying behavior of fabrics. We had found parallel results with the previous studies stated in the literature, which concluded that drying time was mainly related to the spaces inside the fabric and fiber thickness [29-31].

\subsection{Statistical analysis}

Correlation coefficient results are shown in Table 3. We have obtained high correlation values between fabric weight and thermal absorptivity, RWVP, AWVP, air permeability, and transfer wicking. Fabric thickness values also had high correlation coefficient values especially with WER, thermal resistance, RWVP, air permeability, and transfer wicking.

The influence of fabric weight and finishing processes on the thermal comfort characteristics of denim fabrics was evaluated

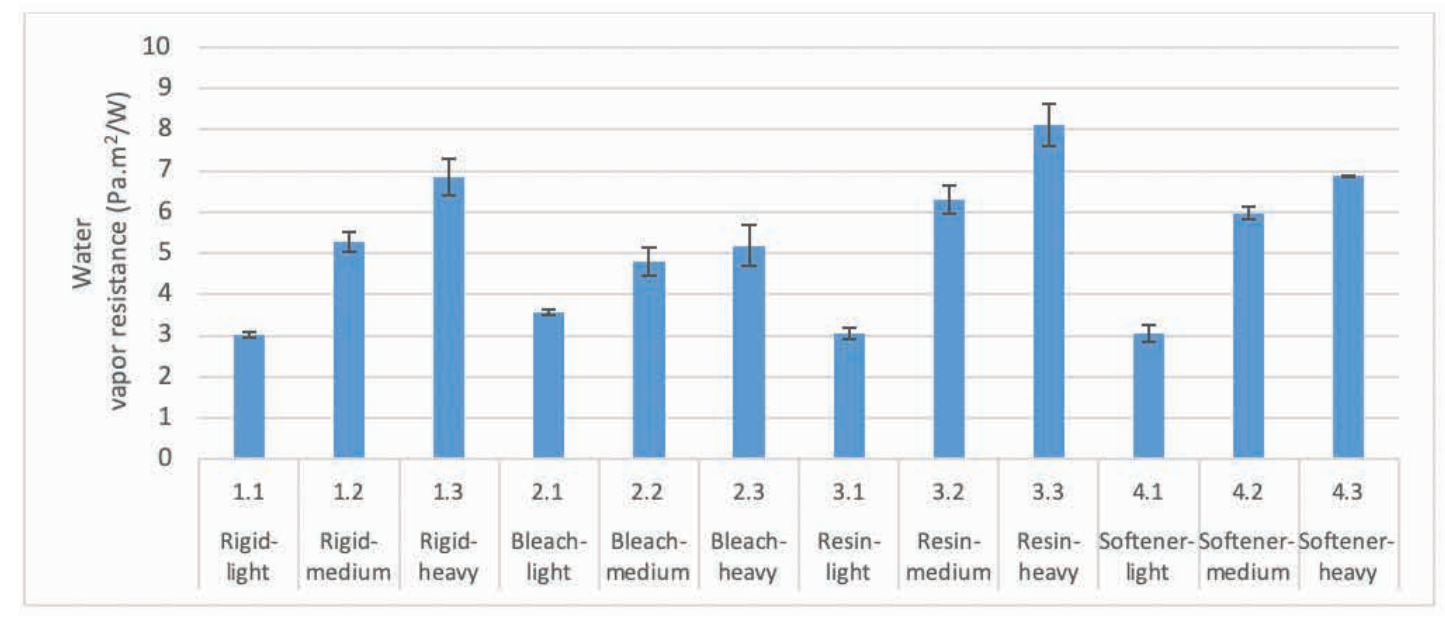

Figure 5. Water vapor resistance results of denim fabrics.

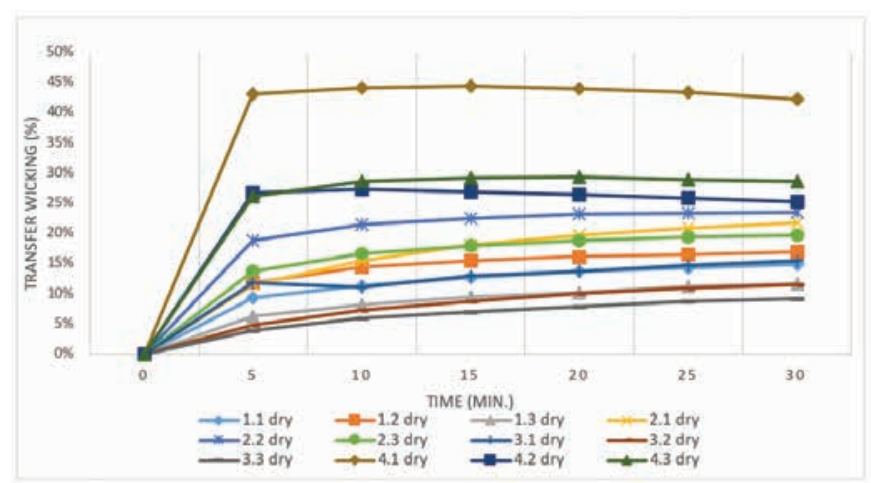

Figure 6. Transfer wicking results of denim fabrics.

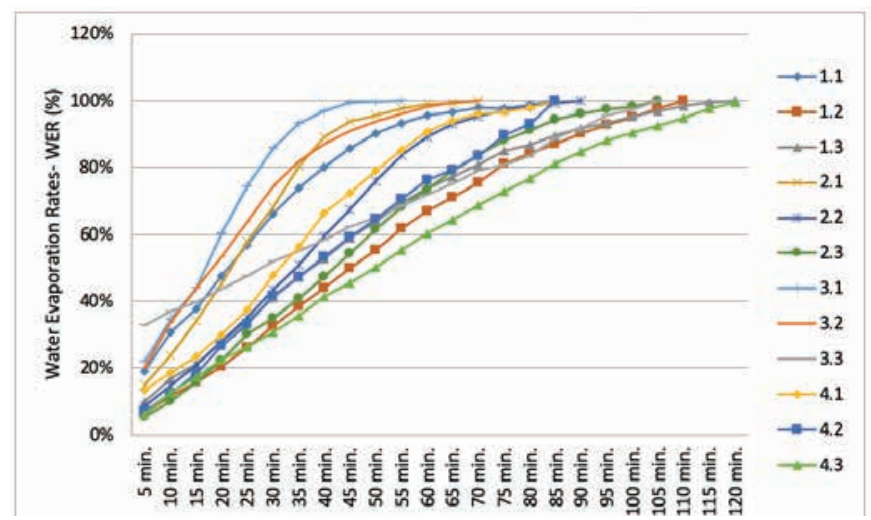

Figure 7. Water evaporation rate values of fabrics. 
with one-way analysis of variance (ANOVA) statistical analysis. One-way ANOVA test results for factor weight are given in Table 4. As it is seen from the table, there is a significant effect of weight type (light, medium, heavy) on transfer wicking, WER, thermal absorptivity, air permeability, RWVP, and AWVP results $(p<0.05)$. The finishing process had been found to be effective especially on thermal resistance values of denim fabrics (Table 5).

Table 3. Pearson correlation coefficients

\begin{tabular}{|c|c|c|}
\hline $\begin{array}{c}\text { Dependent- } \\
\text { independent variables }\end{array}$ & $\begin{array}{c}\text { Pearson } \\
\text { correlation } \\
\text { coefficient }\end{array}$ & p-value \\
evaporation rate (WER) & -0.791 & 0.002 \\
\hline $\begin{array}{c}\text { Weight-water } \\
\text { absorption }\end{array}$ & 0.826 & 0.001 \\
\hline Weight-RWVP & -0.936 & 0.000 \\
\hline Weight-AWVP & 0.902 & 0.000 \\
\hline Weight-air permeability & -0.963 & 0.000 \\
\hline Weight-transfer wicking & 0.960 & 0.000 \\
\hline $\begin{array}{c}\text { Thickness-WER } \\
\text { Thickness-thermal } \\
\text { resistance }\end{array}$ & -0.723 & 0.008 \\
\hline Thickness-RVWP & 0.752 & 0.005 \\
\hline $\begin{array}{c}\text { Thickness-air } \\
\text { permeability }\end{array}$ & -0.646 & 0.023 \\
\hline $\begin{array}{c}\text { Thickness-transfer } \\
\text { wicking }\end{array}$ & 0.868 & 0.005 \\
\hline
\end{tabular}

${ }^{* *}$ Correlation is significant at the 0.01 level (2-tailed).

\section{Conclusion}

This aim of this study was to evaluate the effect of finishing and fabric weight on the thermophysiological comfort properties of $100 \%$ cotton denim fabrics. For this aim, four types of denim fabrics (rigid, resin, bleached, and softened) were produced in three different weight types (light, medium, heavy). Thermal resistance, thermal absorptivity, water vapor permeability, relative water vapor permeability, air permeability, transverse wicking, and WERs were tested after each washing process. The results of the experimental studies explicitly revealed that thermal comfort properties of denim fabrics were significantly influenced by fabric weight and thickness. The higher the fabric weight, the higher the water vapor resistance values and the lower the water vapor permeability and air permeability. Moreover, it was concluded that especially bleaching and softening finishes increased thermal resistance values due to creating more area inside fabric structure. It should be noted that, the results of the presented study are only valid for the fabrics used in this study. In the future, different fabric structures can be evaluated to verify and compare the results.

\section{References}

[1] Adler, M. M., Walsh, W. K. (1984). Mechanisms of transient moisture transport between fabrics. Text Research Journal, 334-343.

[2] Ucar, N., Yilmaz, T. (2004). Thermal properties of 1_1, 2_2, 3 _ 3 rib knit fabrics. Fibres and Textiles in East Europe, 12, 34-38.

[3] Crow, R. M., Osczevski, R. J. (1998). The interaction of water with fabrics. Textile Research Journal, 68, 280-288.

[4] Shinjung, Y., Barker, R. L. (2004). Moisture management properties of heat-resistant workwear fabrics - effects of hydrophilic finishes and hygroscopic fiber blends. Textile Research Journal, 74(11), 995-1000. First Published Nov 1, 2004.

Table 4. Analysis of variance test results for fabric weight

\begin{tabular}{|c|c|c|c|}
\hline Parameters and variables & Df & f & Significance(two tailed) \\
\hline Transfer wicking & 11 & 50.256 & 0.000 \\
\hline Water evaporation rate & 11 & 7.825 & 0.011 \\
\hline Thermal absorptivity & 11 & 11.694 & 0.003 \\
\hline Air permeability & 11 & 54.290 & 0.000 \\
\hline RWVP & 11 & 32.266 & 0.000 \\
\hline AWVP & 11 & 20.230 & 0.000 \\
\hline
\end{tabular}

Factor: weight type.

Table 5. Analysis of variance test results for finishing type

\begin{tabular}{|c|c|c|c|}
\hline Parameters and variables & Df & $f$ & Significance (two tailed) \\
\hline Thermal resistance & 11 & 9.035 & 0.006 \\
\hline
\end{tabular}

Factor: finishing type. 
[5] Yoo, H. S., Hu, Y. S., Kim, E. A. (2000). Effects of heat and moisture transport in fabrics and garments determined with a vertical plate sweating skin model. Textile Research Journal, 70(6), 542-549. First Published Jun 1, 2000.

[6] Zhuang, Q., Harlock, S. C., Brook, D. B. (2002). Transfer wicking mechanisms of knitted fabrics used as undergarments for outdoor activities. Textile Research Journal, 72(8), 727-734.

[7] Shinjung, Y., Eunae, K. (2012). Wear trial assessment of layer structure effects on vapor permeability and condensation in a cold weather clothing ensemble. Textile Research Journal, 82(11), 1079-1091.

[8] Shinjung, Y., Eunae, K. (2008). Effects of multilayer clothing system array on water vapor transfer and condensation in cold weather clothing ensemble. Textile Research Journal, 78(3), 189-197. DOI:10.1177/0040517507078793.

[9] Akçagün, E., Dal, V., Atmaca, M., Ceviz, N., Yıldız, Z., et al. physical properties of denim fabrics after various denim washing formulas. XIII th International Izmir Textile and Apparel Symposium, April 2-5, 2014.

[10] Tarhan, M., Sarışık, M. (2009). A comparison among performance characteristics of various denim fading processes. Textile Research Journal, 79, 4, 301-309.

[11] Dekanića, T., Pušić, T., Soljačić, I. (2015). Influence of special finishes on denim properties. Indian Journal of Fibre \& Textile Research, 40, 170-174.

[12] Dhouib, S., Khedher, F., Sakli, F. (2016). A new approach to predict the fabric shrinkage in denim garments after finishing treatments. The Journal of The Textile Institute, 107(3), 364-375. DOI:10.1080/00405000.2015.1034928.

[13] Ertaş, O. G., Ünal, B. Z., Çelik, N. (2016). Analyzing the effect of the elastane-containing dual-core weft yarn density on the denim fabric performance properties. The Journal of the Textile Institute, 1, 116-126. DOI:10.1080/00 405000.2015.1016319.

[14] El-Ghezal, S., Babay, A., Dhouib, S., Cheikhrouhou, M. (2009). Study of the impact of elastane's ratio and finishing process on the mechanical properties of stretch denim. The Journal of the Textile Institute, 100(3), 245-253. DOI:1080/00405000701757925.

[15] Mezarciöz, S., Toksöz, M. (2014). Investigation of effect of special washing processes on denim fabrics' Properties. Tekstil ve Konfeksiyon, 24(1).

[16] Ayanna, C., Mary, A. M., Mary, A. (2006). Garment washed jeans: Impact of launderings on physical properties. International Journal of Clothing Science and Technology, 18(1), 43-52.

[17] Nasr, L., Ayda, B., Foued, K., Mohamed, H., Saber, B. A., et al. (2017). Effect of finishing resins on mechanical and surface properties of cotton Denim fabrics. The Journal of the Textile Institute, 108(11), 1863-1870. DOI:10.1080/004 05000.2017.1297015.
[18] Özdil, N. (2008). Stretch and bagging properties of denim fabrics containing different rates of elastane. Fibres \& Textiles in Eastern Europe, 1, 63-67.

[19] Hes, L., Mangat, M. M. (2010). The effect of industrial washing on thermal comfort parameters of denim fabrics. 7th International Conference - TEXSCI 2010, September 6-8, Liberec, Czech Republic.

[20] Haq, U. N., Khan, M. M. R., Khan, M. R. (2015). Investigation of the bulk, surface and transfer properties of chlorine bleached denim apparel at different condition. European Scientific Journal, 11(12), 213-226.

[21] Halleb, N. A., Sahnoun, M., Cheikhrouhou, M. (2015). The effect of washing treatments on the sensory of denim fabric. Textile Research Journal, 85(2), 150-159.

[22] Çoruh, M., Vural, T., Çoruh, E. (2011). A scale development study to evaluate the physical comfort of denim jeans. Tekstil ve Konfeksiyon, 1, 77-81.

[23] Eryuruk, S. (2019), "The effects of elastane and finishing processes on the performance properties of denim fabrics", International Journal of Clothing Science and Technology, Vol. 31 No. 2, pp. 243-258. https://doi.org/10.1108/ IJCST-01-2018-0009

[24]Eryuruk, S. (2019), "The effects of elastane and finishing properties on wicking, drying and water vapour permeability properties of denim fabrics", International Journal of Clothing Science and Technology, Vol. aheadof-print No. ahead-of-print. https://doi.org/10.1108/ IJCST-01-2019-0003

[25] Hes, L., De Araujo, M., \& Djulay, V., 1996, "Effect of mutual bonding of textile layers on thermal insulation and thermal contact properties of fabric assemblies", Textile Research Journal, 66, 245-250.

[26] ISO 11092:2014 Textiles -- Physiological effects -Measurement of thermal and water-vapour resistance under steady-state conditions (sweating guarded-hotplate test).

[27] ISO 9237:1995. Textiles-determination of permeability of fabrics to air.

[28] Fangueiro R, Filgueiras A, Soutinho $F$, et al. Wicking behavior and drying capability of functional knitted fabrics, Textile Res J 2010; 80(15): 1522-1530.

[29] Laing RM, Wilson CA, Gore SE, et al. Determining the drying time of apparel fabrics. Textile Res J 2007; 77(8): 583-590.

[30] Patnaik A., Rengasamy RS., Konthari VK, Ghosh A., Wetting and wicking in fibrous materials, Textile Progress, 2006, 38, 1-105.

[31] Prahsam C., Barker RL.,2005, Gupta BS., Moisture vapor transport behavior of polyester knit fabrics, Textile Research Journal, 75, 4, 346-351 